Revista Iberoamericana, Vol. LXVI, Núm. 191, Abril-Junio 2000, 393-405

\title{
LA NEGOCIACIÓN DE LAS DIFERENCIAS SOCIALES EN MARCOS AGUINIS: DESCOLONIZACIÓN DE LA IDENTIDAD CULTURAL JUDÍA ANTE LA ADVERSIDAD
}

\author{
POR \\ Ignacio López-CaLvo \\ California State University, Los Angeles
}

La obra del argentino Marcos Aguinis se adentra en las profundidades del problema de la opresión, la identidad y las fronteras culturales del pueblo judío. Así ocurre tanto en las novelas Refugiados, La gesta del marrano o La matriz del infierno, como en los cuentos "El profeta de Nínive” y "Capítulo excluido"1 o en ensayos incluidos en su colección El valor de escribir. Si bien su obra abarca muchos otros temas, este aspecto en concreto se puede enmarcar en el surgimiento de una literatura judeo-argentina que, como advierte Lindstrom, surge a raíz de los esfuerzos de la Delegación de Asociaciones Israelitas Argentinas: "With the emergence in the 1930s of fascism and renewed anti-Semitism, a number of Jewish leaders and intellectuals began to show a greater readiness to admit publicly that the Argentine Jewish community needed special care and advocacy beyond the general protection offered by the pluralism of the national melting pot” (Lindstrom 22-23). Efectivamente, Aguinis es uno de estos autores que reconocen abiertamente su origen y se concentran en asuntos relevantes para el pueblo judío. ${ }^{2}$

En los textos mencionados cada momento histórico, por remoto que sea, nos hace cuestionar nuestro presente, que sigue lejos de haber borrado el odio al Otro, a la diferencia. No sólo se ponen en tela de juicio las fronteras físicas o territoriales de Israel, las históricas expulsiones y persecuciones o el cierre de fronteras a refugiados, sino que cobran aún más importancia las fronteras culturales y mentales del pueblo judío. Con frecuencia la identidad de los personajes se mantiene oculta o alienada y, paradójicamente, sólo la persecución, el sufrimiento o la muerte hacen que salgan a flote las raíces y los lazos entre los diferentes individuos y comunidades judías. A pesar de la variedad de temas y coordernadas espacio-

\footnotetext{
${ }^{1}$ Incluidos en la colección Y la rama llena de frutos. Todos los cuentos.

2 Entre muchos otros escritores judeo-argentinos podemos incluir a Marcos Ricardo Barnatán, Isidoro Blaisten, Aída Bortnik, Antonio Elio Brailovsky, Humberto Costantini, Alicia Dujovne Ortiz, Samuel Eichelbaum, Ricardo Feierstein, Manuela Fingueret, Luisa Futoransky, Alberto Gerchunoff, Nora Glickman, Gerardo Mario Goloboff, Jorge Goldenberg, Daniel Gutman, José Isaacson, Bernardo Kordon, José Luis Najenson, Pedro Orgambide, Samuel Pecar, Alejandra Pizarnik, José Rabinovich, Andrés Rivera, Germán Rozenmacher, Hebe Serebrisky, Ana María Shua, Alicia Steimberg, Mario Szichman, César Tiempo (Israel Zeitlin), Jacobo Timerman, Eliahu Toker, David Viñas y Bernardo Verbitsky. Para una selección más extensa se pueden consultar los dos tomos del libro de Ana E. Weinstein y Miryam E. Gover de Nasatsky, Escritores judeo-argentinos. Bibliografía 1900-1987 o el artículo de Saúl Sosnowski “Contemporary Jewish-Argentine Writers: Tradition and Politics”.
} 
temporales de las novelas, cuentos y ensayos, existe tal coherencia que el lector tiene la sensación de estar leyendo siempre una misma novela, que se extiende por diferentes períodos de la historia: desde la época la Inquisición en la Península Ibérica y Latinoamérica, pasando por el Holocausto hasta llegar a la creación del estado de Israel y los enfrentamientos bélicos árabe-israelíes.

El antisemitismo es, sin duda, uno de los prejuicios más antiguos y duraderos que ha padecido la humanidad. A lo largo de esta dramática peripecia los judíos han creado una especie de frontera nacional portátil, que se sustancia en su libro sagrado. Hasta la relativamente reciente creación del estado de Israel, la comunidad judía—junto con la gitana o romaní-se ha distinguido de muchas otras no por las fronteras territoriales nacionales, sino por su continua diáspora, que ha terminado por caracterizarlos como pueblo. ${ }^{3} \mathrm{Ni}$ siquiera hoy en día el contar con un territorio propio como el de Israel ha cambiado esta concepción. Así, Aguinis en su primera novela, Refugiados (1969), que fue reeditada en 1976 bajo el título de Refugiados: crónica de un palestino, podemos ver la separación y la creación de fronteras internas que se da en el seno del pueblo judío. En opinión del refugiado palestino—que en pasajes como el siguiente tiene la función de portavoz del autor—se debe extender una línea divisoria entre los judíos de dentro y fuera de Israel:

Creo justo diferenciar a los judíos de Israel de los que no viven en Israel. Los primeros libraron una guerra contra nosotros y nos expulsaron de Palestina. Es cierto que los judíos de todo el mundo apoyaron esa acción y se regocijaron con su triunfo sobre los ejércitos árabes. Pero la usurpación la efecturaron los judíos de Israel y son ellos los que deberían restañar nuestras heridas (Refugiados 29).

En respuesta a lo que el protagonista de Refugiados denomina la “usurpación territorial sionista” (38), otro personaje, el doctor Freytag, le intenta convencer infructuosamente de que sus problemas son principalmente una condición mental. Para ello, se pone a sí mismo como ejemplo: “- Usted es un refugiado, como lo he sido yo y...” (67). Ante la sorpresa del protagonista por el uso del pretérito perfecto, Freytag le augura que con el paso del tiempo, él también dejará de sentirse refugiado, y no precisamente por haber vuelto a su hogar. En su opinión, uno puede llegar a sentirse en su patria y encontrar su identidad en la diáspora, por medio de la solidaridad con los que también sufren. Se puede alcanzar la felicidad — según él— por medio de la compasión por el prójimo y su consuelo. De otro modo, el sentimiento de desarraigo aumenta y el refugiado puede convertirse en un hipocondríaco, que padece males imaginarios para los que no existe cura. Ni siquiera anhela la vuelta al hogar, ya que llevaría consigo la expulsión de las nuevas familias establecidas allí, con lo que continuaría el espiral a la perpetuidad. El doctor Freytag cuestiona asimismo

\footnotetext{
${ }^{3}$ En este contexto, Ricardo Feierstein sostiene: “No escapamos al anatema de la errancia; el exilio interior que llevamos adherido a la piel nos acompaña desde siempre. La peregrinación en pos de orígenes y genealogías confluye irremediablemente, en algún momento, en Jerusalem" ("Mestizo en construcción” 238). De manera similar, la mexicana Margo Glantz asegura: “The feeling of exile, which is typical of the Jew, has followed me just the same-whether it is an exile from God, from the Promised Land of from oneself-as was the case with Walter Benjamin” (Véase DiAntonio y Glickman 19).
} 
el uso del término “refugiado de Palestina” por parte del protagonista cuando, en realidad, la mayoría de ellos siguen viviendo en Palestina, si bien en otra área. En su opinión, los países árabes han usado a los refugiados internos palestinos como instrumento político contra un país que supo asimilar a sus propios refugiados: "Israel demostró al mundo que los refugiados, lejos de constituir una carga, son un factor de progreso. De ese modo, cerca de medio millón de desplazados han sido absorbidos e Israel perdió un valioso instrumento político que podría utilizar ahora para neutralizar la propaganda deshonesta de los gobiernos árabes” (Refugiados 148). Otro personaje de la novela, Ignacio, pone en duda la misma esencia del nacionalismo árabe: “Aceptar que el único factor aglutinante efectivo de los países árabes constituye su odio común contra Israel, es poner en tela de juicio la posibilidad concreta de esa unidad” (128). Según él, el liderazgo en la comunidad árabe se consigue cuando se es más agresivo con Israel que los demás. Propone la anexión por parte de Jordania de seis mil kilómetros de territorio palestino, como prueba de que existían intereses bien diferentes del de la hermandad árabe. Para él, la guerra no la deseaban los árabes sino sus reyes y por eso la perdieron. Curiosamente, en la problematización del nacionalismo tanto de los judíos como de los árabes, Aguinis parece coincidir con Edward Said (uno de los portavoces de la autodeterminación de Palestina y miembro del Consejo Nacional Palestino) cuando éste denuncia: "in Post-colonial national states, the liabilities of such essences as the Celtic spirit, négritude, or Islam are clear: they have much to do not only with the native manipulators, who also use them to cover up contemporary faults, corruptions, tyrannies, but also with the embattled imperial contexts out of which they came and in which they were felt to be necessary" (Culture and Imperialism 16).

Volviendo a Refugiados, el doctor Freytag indica que, después del armisticio, en lugar de aceptar la derrota, "el deseo de borrar con sangre la mancha de sangre, mantiene vivo el odio árabe contra Israel, que ya desbordó el interés económico y las posibilidades políticas para entrar en el campo de las fijaciones obsesivas, psicopáticas” (129). Estos comentarios coinciden con la idea que tiene Neil Lazarus del reduccionismo de la retórica anticolonialista africana:

It implied that there was only one struggle to be waged, and it was a negative one: a struggle against colonialism, not a struggle for anything specific [...] Their heavy emphasis on fraternalism blinded them to the fact that within the movement there were groups and individuals working with quite different, and often incompatible, aspirations for the future (5).

En el corazón de la novela, la relación de amor/odio entre la israelí Myriam y el palestino simboliza el conflicto árabe-israelí. Myriam nace en un barco de refugiados judíos frente a las costas de Palestina y su vida resume la epopeya de su pueblo, con sus luchas y su desesperación. Su odisea emblematiza la protesta contra la ambigua política imperialista de Inglaterra y el limitadísimo número de licencias de inmigración a Palestina que concedió a los judíos. Sin embargo, Myriam es uno de los personajes más optimistas de la novela: su gran sueño es ver un estado palestino de mayoría árabe junto a otro israelí de mayoría judía. El protagonista, en contraste, es el abanderado del deseo palestino de dar marcha atrás a la Historia, de la frustración de un pueblo tantas veces engañado y explotado. La 
transformación del concepto de otredad en la mente del protagonista palestino gracias a sus conversaciones con Myriam, se propone como metáfora optimista de una futura reconciliación entre dos pueblos enfrentados.

Varios críticos han cuestionado el planteamiento utilizado en la novela. Mientras que Martha Paley Francescato afirma que la obra está "escrita desde el punto de vista del palestino, es un intento de ponerse de su lado, mostrar su emoción, su lealtad y sufrimiento" (21), a juicio de Judith Morganroth, la novela se apropia del discurso palestino y es "an apologetics seeking to convince the Palestinian (and the reader) of Zionism's definition as a movement of national liberation, of Israel's right to exist, of the willingness of liberal Israelis to establish the solution proposed by Myriam” (140). Sin embargo, en defensa del argumento de Refugiados, Morganroth aclara que se trata de la aplicación a las relaciones socio-políticas de la siguiente teoría psicoanalítica: “processes that define the self overlap with processes by which we project ourselves into images of the Other" (140). En efecto, éste parece ser el planteamiento de Aguinis. El desvelamiento de la identidad oculta descubre que la motivación de una persona puede tener a veces un origen cuestionable, como puede ser el sentimiento de culpabilidad a consecuencia de la decepción por la actitud paterna. Ése es el caso del personaje árabe Omar Dakajni, cuyo comportamiento colérico y fanático se debe a la vergüenza que siente por el antinasserismo y antibeligerancia que propugnó su padre al final de su vida. Naomi Lindstrom opina que esta novela de Aguinis ${ }^{4}$ proporciona una articulada serie de argumentos en defensa del establecimiento del estado de Israel, al mismo tiempo que se compadece y simpatiza con la causa palestina (35). ${ }^{5}$

Aguinis vuelve a examinar la polémica árabe-israelí en su ensayo La cuestión judía vista desde el Tercer Mundo y en el capítulo “Miedo de árabes y miedo de judíos,” incluido en su colección de ensayos El valor de escribir. En este último trata de llegar a la etiología de ese mutuo temor por medio de un breve estudio histórico de la opresión y frustración histórica de ambas comunidades. Los árabes, oprimidos y humillados por tártaros, españoles, franceses, turcos y británicos, escogen a los judíos como chivo expiatorio de su frustración. La ira acumulada en siglos de desastres se ve concentrada en Israel, el nuevo enemigo que amenaza su tierra y su cultura. Sin embargo, este diminuto adversario consigue derrotarlos. Seguidamente, Aguinis equipara las accidentadas historias de los pueblos judío y árabe: ${ }^{6}$ los judíos fueron traicionados por la comunidad internacional durante el Holocausto y después por la Organización de las Naciones Unidas, que les había prometido la protección de Israel. Una vez más sobreviven tras la Guerra de los Seis Días animados por el hecho de que perder la guerra habría supuesto su desaparición (El valor de escribir 110-115). Otro

\footnotetext{
${ }^{4}$ Al que denomina, no sin cierta ironía, "the great diplomat of progressive Jewish social thought in Argentina" (35).

5 Lindstrom sostiene que el esfuerzo de Aguinis "is not only about conflicts in the Middle East, however. It is also about how to sustain an Argentine position that might be considered Jewish or proJewish in a political culture grown hostile to such an outlook. Aguinis was concerned that intimidation might prevent Jewish Argentines, and others who might support Israel's right to exist, from stating their views" (35).

${ }^{6}$ En La gesta del marrano y el "Capítulo excluido" que cierra la colección de cuentos "Y la rama llena de frutos. Todos los cuentos” (1986), se entrecruzan asimismo las historias de sufrimiento de los pueblos negro e indígena con el judío.
} 
de los esfuerzos etiológicos aparece en Un país de novela. Viaje hacia la mentalidad de los argentinos, ensayo en el que Aguinis asegura que el odio a la diferencia y las ganas de hacer desaparecer al otro, son rasgos generales de la humanidad, y no sólo de una cultura. Se trata, a su juicio, de una forma de descargar el autodesprecio. Cuando no se logra, se acepta la condición de inferioridad.

Siguiendo el camino trazado por Las genealogías, de la mexicana Margo Glantz, A estranha nação de Rafael Mendes, del brasileño Moacyr Scliar, y Mestizo, del argentino Ricardo Feierstein, en La gesta del marrano el protagonista recupera la memoria y la identidad cultural perdidas gracias a que su padre le revela su origen judío. Leonardo Senkman explica cómo hasta hace poco las novelas de los escritores judíos latinoamericanos celebraban América como la tierra del futuro, y se preocupaban por el tiempo presente o el futuro, pero casi nunca por el pasado. En cambio, una generación más tarde los escritores judíos abandonan aquellos sueños utópicos y se enfocan en la trágica realidad social de sus países (Senkman 33-34). Sin duda, Marcos Aguinis forma parte de esta nueva corriente literaria, si bien prefiere que no se le integre en la llamada "nueva novela histórica”, pues considera que este subgénero tiende a violar los datos históricos, con los que él suele ser muy cuidadoso (Barnabe, “El escritor Marcos Aguinis”). Juan Torres-Pou tampoco incluye La gesta del marrano en la "nueva” novela histórica7 a causa de su monoglosia. Según explica, la nueva novela histórica y la novela posmodernista cuestionan "el significado único de todo discurso", mientras que "toda novela que haga suyo un discurso ideológico de tipo étniconacionalista y se defina de acuerdo con el mismo, por su misma esencia, no puede ironizar, cuestionar o poner en tela de juicio el discurso ideológico en que se sostiene” (40).

En La gesta del marrano Francisco - un protagonista de tintes autobiográficos ${ }^{8}$ siente el deber de corregir la traición de su padre "reconciliado" y degradado por el sambenito, quien bajo los efectos de la tortura inquisitorial, ${ }^{9}$ había denunciado a otros compañeros de fuga. Al menos, los estériles esfuerzos del protagonista tienen un efecto catártico para su orgullo tantas veces mancillado. La acción tiene lugar en el trágico momento de la represión del Santo Oficio en las colonias. La toma de conciencia de Francisco nace al presenciar la discusión entre Diego López de Lisboa y José Ignacio Sevilla, en la que confiesan sus temores y muestran sus heridas sin cicatrizar: "Integraban

\footnotetext{
7 Según Seymor Menton define la nueva novela histórica en su estudio Latin America's New Historical Novel, 1949-1979.

${ }^{8}$ Francisco es un personaje judío que estudia medicina en Lima y que se vale de su profundo conocimiento de la fe católica y de las Sagradas escrituras para refutar las contradicciones en la actitud de la jerarquía eclesiástica. Es difícil no hacer un paralelo con Marcos Aguinis, el neurocirujano autor de La cruz invertida, y contertulio de Monseñor Justo Laguna en Diálogos sobre la Argentina y el fin del Milenio y Nuevos diálogos.

9 El artículo "La caza de brujas", de su colección El valor de escribir, entronca con La gesta del marrano cuando afirma que el torturador de nuestro tiempo nace del verdugo inquisitorial. En ambas etapas históricas existe idéntica motivación: "La cacería no busca sólo matar brujas, sino imponer la convicción profunda de que existen, y son las responsables de todas las desgracias. Encontrarlas y quemarlas tranquiliza y brinda un gran beneficio adicional: convencer de que el aparato represivo es más necesario que nunca” (El valor 132). La necesidad que tiene el paranoico protagonista Natalio Comte de crear enemigos ficticios es, precisamente, el eje sobre el que gira el grotesco argumento de otra de sus novelas, La conspiración de los idiotas.
} 
una fláccida red de individuos en permanente fuga. Estaban formados por sangre abyecta y debían esmerarse para conseguir el aprecio de los hombres. No bastaba parecer cristianos: debían borrar las impurezas de su origen” (La gesta del 188). Francisco se da cuenta, entonces, de la posibilidad de que la religión de su pueblo no sea la única causa de las persecuciones, sino que puede que también lo sea su historia: "Los judíos somos el pueblo de las Escrituras, del Libro. La historia es libro, letra escrita. ¡Qué paradoja!, ¿no? Ningún otro pueblo ha cultivado tanto la historia y, al mismo tiempo, es tan obstinadamente castigado por ella” (La gesta del 330). El protagonista basa la identidad judía y el hogar nacional en el texto sagrado. Las lecturas y análisis del Libro los ha acompañado hasta en los peores momentos sin abandonarlos nunca, y su presencia los ha salvado sistemáticamente de su desaparición como cultura. Aunque las interpretaciones puedan haber sido distintas, la mera presencia del texto ha servido como elemento aglutinador que da coherencia a su tradición. A sabiendas de esta realidad, el método de subyugación del otro que utiliza el opresor de la novela es el de anular su historia, que emblematiza el Libro. Los cristianos pretenden borrar la historia judía, como quieren eliminar igualmente la cultura indígena, sus nombres, sus dioses y su lengua. Uno de los personajes, José Ignacio Sevilla, insiste en que no se puede borrar la memoria a voluntad, y que si se olvidara completamente, se correría el peligro de dejar de ser uno mismo. En cambio, Diego López de Lisboa le advierte que la historia es un lastre inútil que puede significar la sentencia de muerte para el judío. En realidad, La gesta del marrano es, además de un libro de viajes en el sentido geográfico (pues los protagonistas deben huir de Ibatín a Córdoba, Lima y Santiago de Chile), la historia de un viaje desde el olvido a la memoria. La vida del protagonista representa un canto a la libertad no sólo del pueblo judío, sino también del ser humano- en especial de los grupos marginados - frente al oscurantismo religioso y el totalitarismo. En el transcurso de ese viaje Francisco va perdiendo poco a poco su inocencia, y su personalidad queda modelada por la imagen que la sociedad tiene de él y de su grupo religioso. Aunque las instituciones católicas le hacen sentirse un indeseable, va tomando conciencia de la injusticia que sufre su pueblo, al mismo tiempo que ante sus ojos se abre la odisea de su familia y el pasado sefardí. Los relatos que escucha son su historia y aprende a amarla contrastando dos perspectivas: la de José Ignacio de Sevilla, que la ama con todas sus consecuencias, y la de Diego López de Lisboa, quien se ha visto obligado a aborrecerla, negándose, por tanto, a sí mismo. Con todo, decide seguir adelante, aunque el sentido común le advierte que la memoria es una amenaza para su propia vida. Ya en las primeras páginas de la novela se nos avisaba del peligro: “Su mayor placer-más que el descanso, más que la sabrosa conversación—era mantener fresca su memoria y ejercitar la de sus hijos. El cuidado de la memoria no era una predilección inocente ni desprovista de riesgos” ( $\mathrm{La}$ gesta del 19-20).

El padre de Francisco, Diego Núñez da Silva, le asegura que el judaísmo es algo mucho más profundo que la religión; algo que posiblemente tenga que ver con la historia o el destino común. Dejar de ser judío es dejar de ser uno mismo, por eso — sostiene su padrelos judíos se han visto obligados a fingir, ser falsos y mantener las apariencias. En esta breve conversación se encuentra quizá el germen de la novela. Aquí nace la rebelión del protagonista y su obstinado deseo de quitarse la máscara. Francisco se da cuenta de que el obligar a alguien a olvidar su pasado no es más que una astuta y eficaz táctica de dominación. 
Los personajes de La gesta del marrano caracterizan al pueblo judío por su capacidad para retener información histórica y repetirla en un determinado momento. Sin embargo, más que la memoria, lo que hace de Francisco un personaje singular no es su función retentiva, sino su capacidad creadora e imaginativa. Harto de almacenar información y esconderla, decide utilizarla en defensa de la libertad de su comunidad, sacrificando su bienestar y el de su familia. Su imaginación creadora (que nace, precisamente, de su memoria de los hechos de Cristo) le hace volar al futuro y le permite crear un proyecto de liberación. Pronto deja de estar volcado al pasado y, tras la etapa de aprendizaje en el convento, opta por una fe activa, ansiosa de justicia. Se vale de su aprendizaje mecánico y memorístico como base para aprehender el sentido de la estructura abstacta de su sociedad. En contraste, otros personajes como Diego López de Lisboa, se rinden y en lugar de luchar por su libertad religiosa, optan por el olvido en beneficio de su propia supervivencia. López trata por todos los medios de sepultar en su subconsciente tanto las enseñanzas de sus antepasados, como el sufrimiento y las injusticias padecidas por su pueblo. Sin embargo, y siguiendo las teorías de Freud, ${ }^{10}$ la desaparición total de los recuerdos no es posible. Los olvidos motivados por la represión devienen la base de la conducta neurótica de personajes como el Burguense, quien, en su afán de esconder su origen hebraico, se convierte en extremista del cristianismo. Este personaje histórico, que muestra las misteriosas ramificaciones del poder opresivo, escoge precisamente el camino contrario que el protagonista. Escribe Scrutinio Scripturarum, un manual dedicado a debatir los argumentos judíos, en el que pone sus conocimientos de la religión judía al servicio del cristianismo. La voz narrativa menciona a otros judíos que se hicieron dominicos, la orden más cercana a la Inquisición, e incluso llegaron a ser obispos. El temor omnipresente que inunda a la comunidad judía hace que de la solidaridad se pase al odio correligionario e incluso al odio a sí mismo. ${ }^{11}$ El mismo Francisco se autoflagela en su juventud y se desprecia por ser judío. Pero con los años, su conciencia moral y el sentido de la responsabilidad para con su comunidad se afianzan, al mismo tiempo que va desenmascarando la manipulación a que se han visto sometidos. Su pueblo ha sido coaccionado y no puede ser libre por miedo al castigo. Sólo una vez que Francisco consigue superar su temor a las represalias, puede luchar contra dos grandes enemigos: la falta de libertad religiosa de su pueblo y su propio miedo. Poco a poco va conquistando su libertad interna, lo que hace válida su lucha a pesar de que nunca llegue a conseguir la libertad externa. En realidad, su búsqueda de armonía y autorrealización no se ve completa hasta el momento de su muerte en la hoguera. Junto a la tristeza por el injusto final reservado al protagonista, el lector tiene la sensación de que su imparable motivación para llevar a cabo sus ideales alcanza su recompensa, en cierto modo, con el ritual injusto de su muerte. Francisco desea ser un mártir de la religión judía y por tanto, la muerte en la hoguera para él es una experiencia alguedónica, de dolor y placer a un mismo tiempo. Su educación en el convento le ha permitido conocer los "beneficios" de la autoflagelación, el cilicio y otras formas de autocastigo, como una vía de purificación.

\footnotetext{
10 Marcos Aguinis es doctor en medicina y cirujano, especializado primero en neurocirugía y luego en psicoanálisis.

${ }^{11}$ Como vemos en el cuento "Consorcio en la tempestad”, incluido en Y la rama llena de frutos. Todos los cuentos, el miedo lleva a la sociedad a una irremisible falta de solidaridad.
} 
El dolor físico y psíquico serán el correctivo que lo encamine hacia la salvación de su alma. A la vez, su larga carrera hacia el martirio le va proporcionando algunos incentivos o estímulos, como las audiencias de carácter extraordinario que le conceden los eruditos de la Iglesia católica, y que representan por sí mismas una señal de preocupación y desconcierto por parte de su enemigo. Cada insulto o desplante a la jerarquía eclesiástica va lavando la mancha heredada de las denuncias realizadas por su padre.

La última de sus novelas, La matriz del infierno, gira en torno al Holocausto, un acontecimiento aún mucho más traumático para el pueblo judío que las sucesivas expulsiones o el nacimiento de Israel. Aquí, la imagen idílica de Argentina como el lugar ideal para el asentamiento de los judíos europeos que se observaba en obras anteriores como Los gauchos judíos, de Alberto Gerchunoff, queda fulminada ante el antisemitismo salvaje que contamina a la sociedad. Uno de los protagonistas es Rolf Keiper, un adolescente argentino cuya maleable personalidad ha sido deformada por su instructor Hans Sehnberg y el capitán Botzen. Estos dos personajes, obsesionados por justificar la supremacía germana y el antisemitismo, consiguen convertirlo en un psicópata. Su fe ciega en la autoridad y su disciplina devota, lo llevan a formar parte de la guardia personal de Hitler y a despreciar profundamente la vida humana. ${ }^{12}$ Pero además de la siniestra influencia de Sehnberg y Botzen, la degeneración psicológica de Rolf Keiper tiene sus bases en la dolorosa evocación de imágenes de la infancia. Tras el recuerdo de la humillación de su padre, Ferdinand, por parte el capitán Julius Botzen, comenta: "El hombrón terrible y cruel que pegaba a su madre y a sus hijos se convertía en un sucio bebé” (La matriz 14). Más tarde, cuando Botzen despidió a Ferdinand, Rolf tuvo que ver cómo su padre trató de violar a punta de cuchillo a su propia esposa. Parece también consternado porque presenció la violación de su madre por parte de cuatro soldados. Como los personajes de La gesta del marrano antes mencionados, Rolf reprime sus sentimientos. No consigue hacer frente a estos estigmas infantiles y en consecuencia, continúa el ciclo de abusos al violar y dejar embarazada a Edith Eisenbach, una joven de padre judío. Las contradicciones del romance entre el protagonista palestino de Refugiados y Myriam, se tornan aún más enrevesadas en la atracción mezclada con odio que Rolf siente por Edith en La matriz del infierno. Pero Rolf no es el único que amenaza la vida de esta joven. La madre de su novio Alberto, manipulada por el antisemitismo de su confesor, intenta asesinarla haciéndole montar un caballo peligroso.

El origen del comportamiento patológico de Rolf se halla en el contexto socio-histórico en que se desarrolla su personalidad. Presenciamos su falla trágica en el momento en que el capitán Botzen le pregunta si le interesaría inocorporarse a un grupo de hombres leales al Káiser, decididos a luchar por el retorno de la monarquía. A partir de entonces su personalidad va corrompiéndose progresivamente: mata a un hombre porque no le saluda a la romana, golpea furiosamente a un enfermo mental, viola y se convierte finalmente en un psicópata manipulable. ${ }^{13}$ Cuando sus dos superiores, Sehnberg y Botzen, lo decepcionan,

\footnotetext{
${ }^{12}$ En cierto modo, su actitud nos recuerda a la del protagonista de la novela de Robert Merle, La mort est mont métier.

13 En Carta esperanzada a un general. Puente sobre el abismo Aguinis explica que la persona autoritaria necesita controlar, exteriorizar su sufrimiento en el otro, sometiéndolo: "persigue eterna e inútilmente, con el afán de matar afuera el Satanás que habita en sus entrañas” (110).
} 
se siente traicionado y los asesina. En definitiva, las estructuras sociales corruptas lo han atrapado y pervertido hasta anular su personalidad.

No obstante, en medio de esta deprimente atmósfera el antisemitismo nazi contribuye de forma indirecta a que se limen las diferencias que enfrentaban a los judíos alemanes con los ostjuden rusos y polacos. En otros casos propicia la recuperación por parte de algunos personajes de la identidad cultural perdida. El padre de Edith Eisenbach, Alexander, había permanecido voluntariamente alienado a su identidad judía, y estaba convencido de la imposibilidad de que los nazis llegaran al poder: "Los nazis son bandas de delincuentes que la misma población sofocará. El pueblo se cansará de ellos; son brutos, ignorantes y extraños a nuestra cultura” (La matriz 134). Sólo cuando es agredido a causa de su origen decide identificarse con su pueblo y convertirse en activista, a pesar de la oposición de su esposa Cósima. La ceguera de Alexander lleva al lector a considerar la posibilidad de que la tragedia vuelva a repetirse.

Por otro lado, la novela extiende la responsabilidad del genocidio nazi a países como Estados Unidos, Francia y Polonia, que ofrecieron un respaldo indirecto a Hitler al no frenarlo a tiempo y al cerrar sus fronteras a los refugiados judíos. Por el mismo camino, se critica el antisemitismo de la Iglesia argentina y la pasividad del Vaticano que, salvo en casos aislados, optó por asegurar su propia supervivencia en lugar de enfrentarse al genocidio. ${ }^{14}$ Se sugiere, incluso, que la Iglesia llegó a beneficiarse del nazismo pues "en el país se vivía un renacimiento de la fe bajo la protección del autoritarismo” (La matriz 187-188). Más adelante, Marcos Aguinis cede su opinión personal a un personaje de la novela, el Obispo Preysing, el cual reconoce los errores de la Iglesia:

Los nazis tienen el espantoso mérito de haber sincerado la cosa. ¿Sabe a qué me refiero, Edith? A que dicen sin eufemismos, de manera brutal, lo que indirectamente proponía nuestra prédica: hacerlos desaparecer. Nosotros mediante el bautismo y las expulsiones, los nazis mediante el terror (La matriz 443-444).

En La gesta del marrano Diego Maldonado da Silva comparte la opinión del personaje de La matriz del infierno cuando le explica a su hijo Francisco: "El fondo del conflicto no es religioso. Ellos no anhelan nuestra conversión. No. Eso sería fácil. Ya han convertido a comunidades judías enteras. En verdad, Diego, luchan por nuestra desaparición. La quieren por las buenas o por las malas” (La gesta 49). En otra novela anterior, La cruz invertida, ${ }^{15}$ Aguinis contrastaba la actitud solidaria de los nuevos sacerdotes, cercanos a la teología de la liberación, con la de la Iglesia católica institucional, que aparecía desconectada del pueblo y aliada al poder represivo. Pese al tono reconciliador, veintisiete años más tarde en La matriz del infierno la crítica a la Iglesia se agudiza. Su indolencia con respecto a los acuciantes problemas sociales, queda representada simbólicamente en la descripción de la

\footnotetext{
${ }^{14}$ En su libro Teología de la liberación. Perspectivas Gustavo Gutiérrez protesta: “¿puede decirse honestamente que la Iglesia no interviene en 'lo temporal'? Cuando, con su silencio o sus buenas relaciones con él, legitima un gobierno dictatorial y opresor, ¿está cumpliendo sólo una función religiosa? (113).

15 En 1970 La cruz invertida fue la primera novela latinoamericana a la que se otorgó el Premio Planeta.
} 
pomposa coronación de Pío XII y el entusiasmo con que el sacerdote antisemita Antonio Ferlic espera la llegada del Congreso Eucarístico Internacional que, según él, mejorará la imagen de la Iglesia local y del gobierno. A pesar de que se encierra a varios clérigos en campos de concentración por lo subversivo de sus sermones, la Iglesia argentina de la novela recibe con honores al embajador nazi. Únicamente algunos curas jóvenes y laicos como Edith y Margarete Sommer presentan cierta oposición. La Santa Sede se limita a dictar tímidas protestas que no llegan a tener el alcance necesario para ejercer su poderosa influencia.

La búsqueda en la novela no se limita a la verdad oculta del pasado, sino también y principalmente — a la verdad del presente. La originalidad no está en demostrar que la perspectiva con la que se escribe la historia es la del ganador, o que el discurso es un aliado del poder, sino en proponer el autoconocimiento por medio de la reflexión histórica. La falsa neutralidad del discurso histórico es secundaria a la falta de objetividad con que juzgamos nuestra propia mentalidad. Como asegura Julia Kristeva en su libro Strangers to Ourselves, "we shall never be able to live at peace with the strangers around us if we are unable to tolerate the otherness in ourselves" (191). El otro, el extranjero habita dentro de nuestra propia mente. El texto de Kristeva ofrece una solución al trauma de Rolf, una explicación psicológica de la atracción-repulsa que siente hacia Edith: "By recognizing our uncanny strangeness we shall neither suffer from it nor enjoy it from the outside. The foreign is within me, hence we are all foreigners" (192). Marcos Aguinis presenta una óptica parecida cuando afirma en "Mito y contramito del judío," incluido en El valor de escribir, que "el antisemita deja de odiar al judío en la medida que logra armonizar partes de sí mismo que lo horrorizan. Sólo cuando alcanza la paz con su propio ser deja de necesitar la víctima en quien descargar su intensa producción de veneno” (103).

En el ámbito de la ficción la novela desarrolla las teorías avanzadas en el capítulo "La indagación interminable” (El valor de escribir), en donde se analizaba la imagen del judío mítico en la literatura universal. Junto al resistente mito creado y sostenido por sectores poderosos, aparece el contramito que, en su ímpetu por desengañar a la humanidad sobre los valores del judío y del judaísmo, acaba siendo contraproducente: "En su empeño de réplica, de freno, de contraofensiva, queda tullido por los mismos defectos del mito: la simplicación, el esquema, el maniqueísmo. Antes el judío era el malo, ahora es el bueno; antes el demonio, ahora el querubín” (El valor de escribir 102). Por esta razón, en La matriz del infierno Aguinis se asegura de hacer hincapié en las tensiones internas entre los judíos alemanes y los ostjuden rusos y polacos; el propio Alexander Eisenbach se solía mofar de estos últimos, y afirmaba que "los judíos, en su conjunto, no son tan meritorios ni tan santos" (La matriz 171). A pesar de que la acción tiene lugar en la década de los años treinta, $L a$ matriz del infierno es una novela proyectada al porvenir y con una intención profética. El desarrollo de los eventos históricos constituye la radiografía de una época que sigue afectando nuestro presente histórico, y debe llevarnos a la deconstrucción de nuestra propia psicología y actitud cotidiana. El texto nos demuestra que el hombre de la calle lleva en sus entrañas el germen de la tiranía opresora, y lo demuestra, por ejemplo, en su comportamiento doméstico.

A juzgar por lo visto en algunos de los textos mencionados, la ausencia de un territorio nacional y las expulsiones que han padecido los judíos a lo largo de la historia, lejos de 
eclipsar la afirmación de su identidad como pueblo, parecen haber reforzado su creatividad y su vitalidad cultural. La diáspora se convierte en una forma de vida e inspiración, lo que de ningún modo significa que el judío sea un ser desarraigado y apátrida. En el cuento “El profeta de Nínive” Aguinis problematiza este prejuicio ancestral, que queda desvirtuado en el resto de su obra. El judío quedó fuertemente arraigado a la tierra de Israel, a España en tiempos de la expulsión de los sefarditas, y a todos los países de los que fueron expulsados, incluyendo Alemania. En cierto modo, las premisas del texto de Aguinis coinciden con Shreiber cuando afirma que es posible "to hear not the lament of perpetual exile but an active claim for a diasporic version of home and of identity" (274). El movimiento perpetuo de la comunidad judía a lo largo de la historia ha concedido a su pueblo una concepción errante del hogar nacional. Como se ha demostrado, otro punto esencial en la obra de Aguinis es la concepción de la Historia como un elemento ambivalente. Es la gran fuente de problemas para los judíos pero al mismo tiempo, puede ser un arma para su supervivencia. Cansados de ser discriminados por su herencia cultural y sus creencias, algunos individuos deciden voluntariamente tener mala memoria y olvidar, hasta llegar al auto-odio; otros, en cambio se aferran a sus recuerdos y los usan para su liberación, lo cual acaba por crear divisiones internas. Entonces, ¿cómo se pueden negociar las diferencias en el seno de la identidad cultural? Homi K. Bhabha se hace esta misma pregunta en su introducción a The Location of Culture:

\begin{abstract}
It is in the emergence of the interstices - the overlap and displacement of domains of difference - that the intersubjective and collective experiences of nationness, community interest, or cultural value are negotiated. How are subjects formed "in-between", or in excess of, the sum of the "parts" of difference (usually intoned as race/class/gender, etc.)? How do strategies of representation or empowerment come to be formulated in the competing claim of communities where, despite shared histories of deprivation and discrimination, the exchange of values, meanings and priorities may not always be collaborative and dialogical, but may be profoundly antagonistic, conflictual and even incommensurable? (2).
\end{abstract}

La respuesta que nos ofrece la obra de Aguinis para el caso judío es que a lo largo de su historia, la comunidad hebrea ha conseguido vencer las diferencias internas de su identidad nacional y cultural cuando lo ha requerido la adversidad. Es decir, no nos explica cómo se liman dichas diferencias, sino cuándo. En el momento en que su identidad corre peligro de desaparecer a causa del genocidio o la represión, la mente del judío se descoloniza y la cohesión social entre sus individuos se fortalece y hace patente. En ese momento, deja de tener sentido hablar de construcciones imaginarias de la identidad o de patrias imaginarias.

BiBLIOGRAFÍA

Aguinis, Marcos. Carta esperanzada a un general. Puente sobre el abismo. Buenos Aires: Sudamericana-Planeta, 1983.

La conspiración de los idiotas. Buenos Aires: Emecé, 1978.

La cruz invertida. Barcelona: Planeta, 1970. 
La cuestión judía vista desde el Tercer Mundo. Río Cuarto, Argentina: Librería Superior Editora, 1974.

La gesta del marrano. Barcelona: Planeta, 1992.

Y la rama llena de frutos. Todos los cuentos. Buenos Aires: Sudamericana-Planeta, 1986.

La matriz del infierno. Buenos Aires: Sudamericana, 1997.

Refugiados. Buenos Aires: Losada, 1969.

El valor de escribir. Buenos Aires: Sudamericana-Planeta, 1985.

Un país de novela. Viaje hacia la mentalidad de los argentinos. Buenos Aires: Planeta, 1988.

y Mons. Justo Laguna. Diálogos sobre la Argentina y el fin del Milenio. Buenos

Aires: Sudamericana, 1996. Nuevos diálogos. Buenos Aires: Sudamericana, 1998.

Barnabe, Diego. “El escritor Marcos Aguinis presenta en Montevideo su libro 'La matriz del infierno"” (2 de julio de 1998): 5. Radio El Espectador. Cultura. Uruguay. Internet. 3 en. $1999<$ http://www.espectador.com/text.clt11201.htm>.

Bhabha, Homi K. The Location of Culture. Londres: Routledge, 1994.

DiAntonio, Robert y Nora Glickman (eds.). Tradition and Innovation. Reflections on Latin American Jewish Writing. Albany, NY: State University of New York Press, 1993.

Feierstein, Ricardo. Mestizo. Buenos Aires: Milá, 1988

"Mestizo en construcción." Pluralismo e identidad. Lo judío en la literatura latinoamericana. Buenos Aires: Milá, 1986. 233-238.

Gerchunoff, Alberto. Los gauchos judíos. Buenos Aires: Centro Editor de América Latina, 1968.

Glantz, Margo. Las genealogías. México: M. Casillas, 1981.

Gutiérrez, Gustavo. Teología de la liberación. Perspectivas. Salamanca: Sígueme, 1972.

Kristeva, Julia. Strangers to Ourselves. León S. Rondiez, trad. Nueva York: Columbia University Press, 1991.

Lazarus, Neil. Resistance in Postcolonial African Fiction. New Haven: Yale University Press, 1990.

Lindstrom, Naomi. Jewish Issues in Argentine Literature: From Gerchunoff to Szichman. Columbia: University of Missouri Press, 1989.

Menton, Seymor. Latin America's New Historical Novel, 1949-1979. Austin: University of Texas Press, 1992.

Merle, Robert. La Mort est mon métier. Paris: Éditions Gallimard, 1972.

Morganroth Schneider, Judith. "Marcos Aguinis: Shifting Lines of Difference Between Other and the Self”. Tradition and Innovation. Reflections on Latin American Jewish Writing. Robert DiAntonio y Nora Glickman, eds. Albany, NY: State University of New York Press, 1993. 135-146.

Paley Francescato, Martha. "De Maimónides a marranos: la gesta de Marcos Aguinis”. La gesta literaria de Marcos Aguinis. Ensayos críticos. Juana Alcira Arancibia, ed. San José, Costa Rica: Instituto Literario y Cultural Hispánico, 1998. 17-29.

Said, Edward W. Culture and Imperialism. Nueva York: Knopf/Random House, 1993. 
Scliar, Moacyr. A estranha nação de Rafael Mendes. Porto Alegre, RS: L\&PM Editores, 1983.

Senkman, Leonardo. “Jewish Latin American Writers and Collective Memory”. Tradition and Innovation. Reflections on Latin American Jewish Writing. Robert DiAntonio y Nora Glickman, eds. Albany, NY: State University of New York Press, 1993. 33-43.

Shreiber, Maeera Y. "The End of Exile: Jewish Identity and its Diasporic Poetics”. PMLA 113/2 (1998): 273-287.

Sosnowski, Saúl. "Contemporary Jewish-Argentine Writers: Tradition and Politics". Echad: An Anthology of Latin American Jewish Writings. Roberta Kalechofscky y Robert Kalechofscky, eds. Marblehead, MA: Micah, 1980. 16-29.

Torres-Pou, Juan. "Consideraciones sobre el papel de la historia en la literatura judeolatinoamericana: La gesta del marrano y la "nueva” novela histórica”. La gesta literaria de Marcos Aguinis. Ensayos críticos. Juana Alcira Arancibia, ed. San José, Costa Rica: Instituto Literario y Cultural Hispánico, 1998. 29-45.

Weinstein, Ana E. y Miryam E. Gover de Nasatsky (eds.). Escritores judeo-argentinos. Bibliografía 1900-1987. Buenos Aires: Milá, 1994. 